\title{
$P B S 2$, a yeast gene encoding a putative protein kinase, interacts with the $R A S 2$ pathway and affects osmotic sensitivity of Saccharomyces cerevisiae
}

\author{
GeORge BoguslawsKi* \\ Departments of Medicine and of Microbiology and Immunology, Indiana University School of Medicine, 545 Barnhill Drive, \\ Indianapolis, IN 46202, USA
}

(Received 13 May 1992; revised 13 July 1992; accepted 24 July 1992)

\begin{abstract}
The yeast gene PBS2 encodes a presumed protein kinase. The gene is essential for manifestation of resistance to the antibiotic polymyxin $B$. Deletion of $P B S 2$ enables a ras2-530 null mutant to grow on nonfermentable carbon sources; overexpression of $\mathrm{PBS2}^{+}$enhances viability of a $\mathrm{RAS2} 2^{\mathrm{Val19}}$ mutant. Overexpression of $\mathrm{PBS2}^{+}$also diminishes cellular response to mating pheromone MF $\alpha$. These results suggest that the $P B S 2$ and $R A S 2$ genes affect a common pathway that may communicate with the pheromone response pathway. In addition, disruption of $P B S 2$ renders cells sensitive to high osmolarity: exposure to $0.9 \mathrm{M}-\mathrm{NaCl}$ causes growth arrest, appearance of bizarre morphological forms, and eventual death. A mutation suppressing pbs 2 deletion has been found. That mutation restores full polymyxin B resistance but only partially corrects the osmotic sensitivity defect. These observations indicate that $\boldsymbol{P B S 2}$ is involved in diverse physiological pathways in yeast.
\end{abstract}

\section{Introduction}

Polymyxin B, a complex antibiotic produced by cells of Bacillus polymyxa, is very toxic to bacterial, fungal and animal cells. The drug exerts its effects by damaging the integrity of cell membranes (Storm et al., 1977), and at high concentration it causes cell lysis.

Polymyxin B has several important uses in biological studies. First, high concentrations of the antibiotic, a positively charged molecule, displace calcium ions from anionic phospholipids and cause disorganization of cell membranes (Storm et al., 1977). Thus, the topography of eukaryotic membranes, as well as the role of calcium ions in the maintenance of membrane structure and activity, can be elucidated with the help of this antibiotic (Bearer \& Friend, 1980; Kubesch et al., 1987). Second, the drug produces interesting pharmacological effects. For example, it is one of the most potent neuromuscular blocking agents known (Singh et al., 1980), and it promotes the conversion of membrane acetylcholine receptors from the resting activatable state to the desensitized state (Brazil et al., 1989; Brown \& Taylor, 1983). Third, the antibiotic inhibits $\mathrm{Ca}^{2+}$-activated $\mathrm{K}^{+}$ channels in mouse skeletal muscle (Weik \& Lonnendonker, 1990) and in human red blood cells (Varecka et al., 1987). In addition, polymyxin B interferes with

* Tel. 3172747673 ; fax 3172741587. insulin-induced activation of hexose transport and metabolism in whole animals and in isolated muscle of mice and rats (Amir \& Shechter, 1985; Amir et al., 1987). In Saccharomyces cerevisiae polymyxin B is a powerful inhibitor of mating (Boguslawski, 1986).

Studies on polymyxin $B$ resistance in yeast have revealed the existence of two genes, $P B S 1$ and $P B S 2$ (polymyxin $B$ sensitivity), whose activities are essential for the resistance phenotype (Boguslawski, 1985; Boguslawski \& Polazzi, 1987). The deduced amino acid sequence of the $P B S 2$ gene product bears a strong resemblance to polypeptides of the serine/threonine protein kinase family (Boguslawski \& Polazzi, 1987; Hanks et al., 1988), making it likely that the gene does encode a protein kinase. The pbs 1 mutation confers a high level of resistance to polymyxin B on yeast cells, but only if an intact $\mathrm{PBS2}^{+}$gene is present (Boguslawski \& Polazzi, 1987). Disruption of this gene results in a drugsensitive phenotype. Conversely, overexpression of $P B S 2^{+}$makes cells resistant to the drug even in the wildtype background.

The results discussed in the present communication show that, in addition to abolishing polymyxin $B$ resistance, disruptions in the $P B S 2$ gene can suppress a recessive null mutation of the yeast $R A S 2$ gene, and that overexpression of $\mathrm{PBS}^{+}$attenuates the effect of a dominant $R A S 2^{\text {Val } 19}$ mutation. Furthermore, enhanced expression of $\mathrm{PBS}^{+}$diminishes the ability of cells to 
respond to a mating pheromone. These observations suggest that $P B S 2$ may be a part of the signal transduction circuitry in yeast.

\section{Methods}

Strains. All yeast strains and plasmids used in this work are listed in Table 1. The media, growth conditions, and methods of genetic manipulation have been described by Sherman et al. (1983). YEPD medium contains $2 \%(\mathrm{w} / \mathrm{v})$ glucose, $2 \%(\mathrm{w} / \mathrm{v})$ Bacto peptone and $1 \%$ $(w / v)$ yeast extract. Solid YEPD medium includes $2 \%$ (w/v) agar. All strains described here grow very well on this medium at $30^{\circ} \mathrm{C}$.

Pheromone sensitivity assay. Approximately $10^{7} \mathrm{MATa}$ cells were suspended in $3 \mathrm{ml}$ of $0.7 \%$ agar in water and poured on synthetic minimal medium plates containing the necessary nutrients. After the agar overlay had solidified, sterile filter disks $(6 \mathrm{~mm}$ diameter) were placed on the surface, and synthetic mating pheromone (MF $\alpha_{1}$, Sigma) was applied to each disk. The plates were incubated at $30^{\circ} \mathrm{C}$ for $2-3 \mathrm{~d}$ until the zones of inhibition were easily observed.

Viability assays. The tests were performed essentially as described by Toda et al. (1985). Cells were grown at $30^{\circ} \mathrm{C}$ to stationary phase in liquid minimal medium supplemented with the necessary nutrients, washed with water, and resuspended in starvation medium $(2 \%, w / v$, glucose and $0.17 \%, w / v$, Difco yeast nitrogen base without nitrogen source or the nutrients) at $1 \times 10^{6}$ cells $\mathrm{ml}^{-1}$ (Toda et al., 1985). After $96 \mathrm{~h}$ of shaking at 300 r.p.m. at $30^{\circ} \mathrm{C}$, aliquots were plated on solid YEPD, and viability was determined by counting colonies on each plate after $2 \mathrm{~d}$.

Heat shock. Cells were patched on minimal medium plates supplemented with the necessary nutrients and grown to confluence. The plates were sealed with Parafilm and floated in a $55^{\circ} \mathrm{C}$ water bath. After incubation, the plates were replicated onto YEPD and incubated at $30^{\circ} \mathrm{C}$ for $24 \mathrm{~h}$.
Osmotic sensitivity. Cells were grown in patches on solid YEPD and replica-printed onto YEPD containing $0.9 \mathrm{M}-\mathrm{NaCl}$. The plate was incubated at $30^{\circ} \mathrm{C}$ for $72 \mathrm{~h}$ and photographed. Survival of the cells was tested by incubating the patches on the $0.9 \mathrm{M}-\mathrm{NaCl}$ plate for $9 \mathrm{~d}$ and printing onto fresh YEPD.

Phase-contrast and fuorescence microscopy. Methods described by Adams \& Pringle (1991) were used to assess the effect of high salt concentration on cell morphology. Cells were scraped from a plate of YEPD containing $0.9 \mathrm{M}-\mathrm{NaCl}$, washed, fixed in formaldehyde, and examined microscopically. Rhodamine-phalloidin conjugate (Molecular Probes) was used to determine actin distribution.

Plasmid constructions. Two integrating plasmids were used in this study (Fig. 1). Plasmid YIp5-AN117 carries a $1 \cdot 17 \mathrm{~kb}$ internal fragment (AatII-NarI) of the PBS2 gene in the YIp5 vector (Boguslawski \& Polazzi, 1987). To create a disruption, pbs2-1, the plasmid was digested with the restriction endonuclease $C l a I$. The linear molecule was integrated into the chromosomal site, disrupting the open reading frame at amino acid 141. Alternatively, a deletion, $p b s 2-2$, was created by substituting the Tcr-URA3+ portion of YIp 5 (as a $3.2 \mathrm{~kb} C l a \mathrm{I}-X m n \mathrm{I}$ fragment) for the $1.26 \mathrm{~kb} \mathrm{ClaI-EcoRV}$ portion of the open reading frame of the gene. The resulting plasmid pGB5 was digested with Aat II, and the $4 \cdot 1 \mathrm{~kb}$ fragment was integrated into the chromosome to create $p b s 2-2$ with the protein coding sequence truncated at amino acid 38. Southern analysis confirmed the nature of integration in each case (data not shown), and the two constructions displayed essentially identical phenotypes in the tests described in this communication.

For studies requiring overexpression of $\mathrm{PBS}^{+}$, an episomal plasmid YEp24.PBS2 was constructed. For this purpose, the parent plasmid R5H (Boguslawski \& Polazzi, 1987) was digested with SacI restriction endonuclease, the ends made flush with T4 phage DNA polymerase, and a SalI linker added. After ligation and transformation of Escherichia coli, the plasmid was isolated, digested with DraI and Sall, and a $3.2 \mathrm{~kb}$ DraI-SaII fragment, containing the entire $P B S 2$ gene, was isolated by gel electrophoresis. The purified fragment was ligated into the YEp24 vector that had been digested with PvuII and SalI.

Table 1. Saccharomyces cerevisiae strains and plasmids used in this study

\begin{tabular}{|c|c|c|}
\hline & Genotype or relevant markers & Source or reference \\
\hline \multicolumn{3}{|l|}{ Strains } \\
\hline YNN27 & $M A T \alpha \operatorname{trp1}-289$ ura3-52 & R. W. Davis \\
\hline GBH21 & MAT $\alpha$ trp $1-289$ ura3-52 pbs $1-273$ & Boguslawski (1985) \\
\hline GBH37 & MAT $\alpha$ trp1-289 ura3-52 pbs1-273 pbs2-2 & This work, from GBH21 \\
\hline GBH38 & MAT $\alpha$ trp1-289 ura3-52 pbs $2-2$ & This work, from YNN27 \\
\hline GBH46 & MAT $\alpha$ trp1-289 ura3-52 pbs1-273 pbs2-2 PBS $^{\mathrm{r} *}$ & This work, from GBH37 \\
\hline JC482 & MAT $\alpha$ his4 ura3 leu2 & Cannon et al. (1986) \\
\hline $\mathrm{JC} 302$ & $M A T \alpha$ ras $2-530:: L E U 2^{+}$his 4 ura3 leu 2 & Cannon et al. (1986) \\
\hline GBH74 & MAT $\alpha$ ras $2-530::$ LEU2 ${ }^{+}$his 4 ura3 leu2 pbs $2-1$ & This work, from JC302-26B \\
\hline JC303-58 & $M A T \alpha$ ras2-530::LEU2+ his4 ura3 leu2 yakl(SRA7-14) & Cannon et al. (1986) \\
\hline $\mathrm{X} 10$ & MAT $\alpha$ ras 2-530::LEU2+ his4 ura3 leu2 yakl(SRA7-14) pbs2-1 & This work, from JC303-58 \\
\hline SP1 & MATa leu 2 his 3 ade8 ura3 trpl canl & Toda et al. (1985) \\
\hline GBH83 & MATa leu 2 his 3 ade8 ura 3 trpl canl pbs 2-2 & This work, from SP1 \\
\hline TK161-R2V & MATa leu 2 his3 ade8 ura3 trp1 can1 RAS2 $2^{\text {Val19 }}$ & Toda et al. (1985), from SP1 \\
\hline GBH65 & MATa leu2 his 3 ade8 ura3 trp1 can1 RAS2 Val 19 pbs $2-2$ & This work, from TK161-R2V \\
\hline \multicolumn{3}{|l|}{ Plasmids } \\
\hline YEp24.PBS2 & Episomal, $\mathrm{Ap}^{\mathrm{r}}, U R A 3^{+}$, complete $P B S 2^{+}$gene & This work \\
\hline YIp5-AN 117 & Integrating, $\mathrm{Ap}^{\mathrm{r}}, U R A 3^{+}$(see Fig. 1) & Boguslawski \& Polazzi (1987) \\
\hline pGB5 & Integrating, $A p^{r}, T^{r}, U R A 3^{+}$(see Fig. 1) & This work \\
\hline
\end{tabular}

* Strain GBH46 carries a mutation that restores polymyxin B resistance (PBSr). The nature of this mutation has not been elucidated (see text for details). 

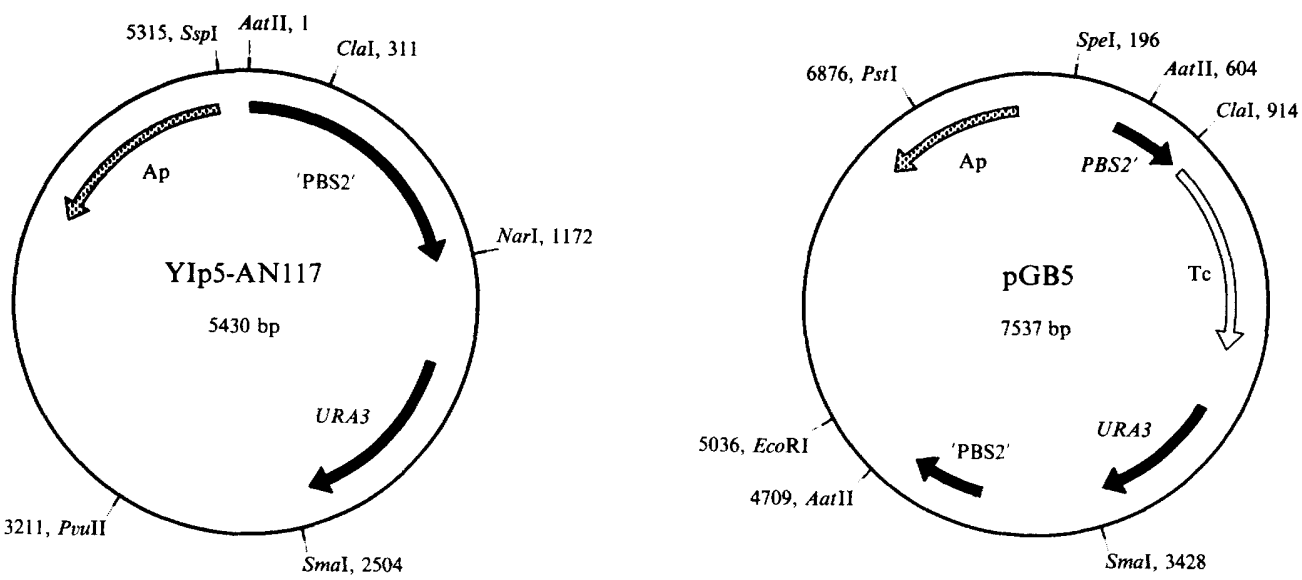

Fig. 1. Integrating plasmids YIp5-AN117 and pGB5. The details of plasmid construction are described in Methods. The PBS2 sequences used to promote chromosomal integration are shown as filled arrows.

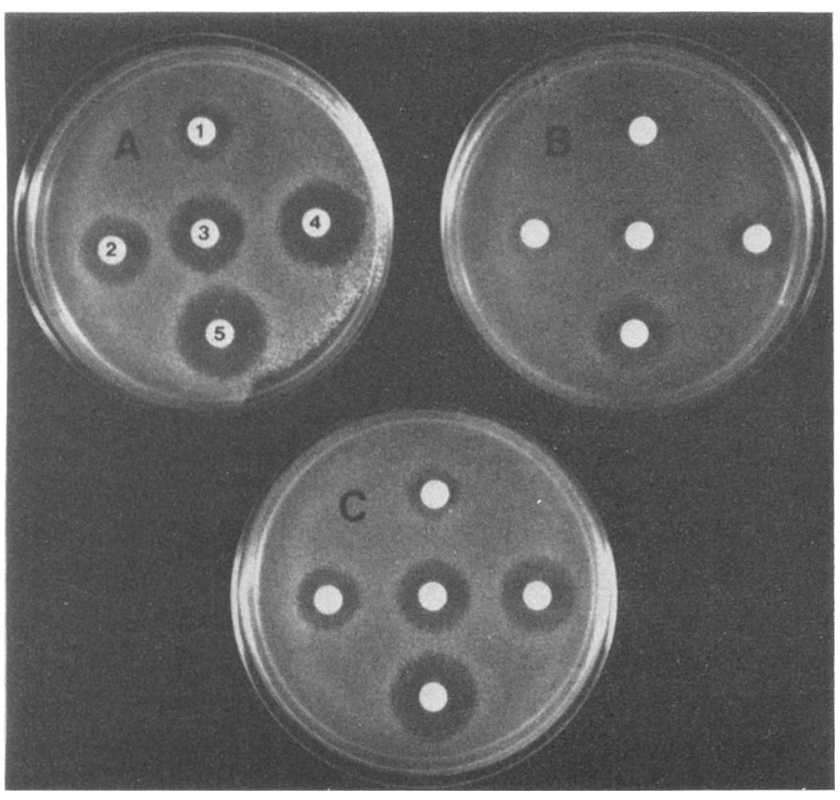

Fig. 2. Reduction of sensitivity to mating pheromone $\alpha$ by overexpression of $P B S 2^{+}$. Increasing amounts of the synthetic pheromone $\mathrm{MF} \alpha_{1}$ were applied to each filter disk (disk $1,1.8 \mu \mathrm{g} ; 2,3.6 \mu \mathrm{g} ; 3,5.4 \mu \mathrm{g} ; 4$, $7.2 \mu \mathrm{g} ; 5,10.8 \mu \mathrm{g}$ ). The plates were incubated for $2 \mathrm{~d}$ at $30^{\circ} \mathrm{C}$. A, GBH83, pbs2-2; B, SP1 transformed with YEp24.PBS2; C, SP1 transformed with YEp24 vector.

\section{Results}

Previous studies revealed that polymyxin B is a potent inhibitor of mating in Saccharomyces cerevisiae (Boguslawski, 1986). This observation suggested that genes involved in polymyxin B resistance may interact with some elements of signal transduction pathways in yeast. As shown in Fig. 2, overexpression of $P B S 2^{+}$considerably reduces sensitivity of a cells to the mating

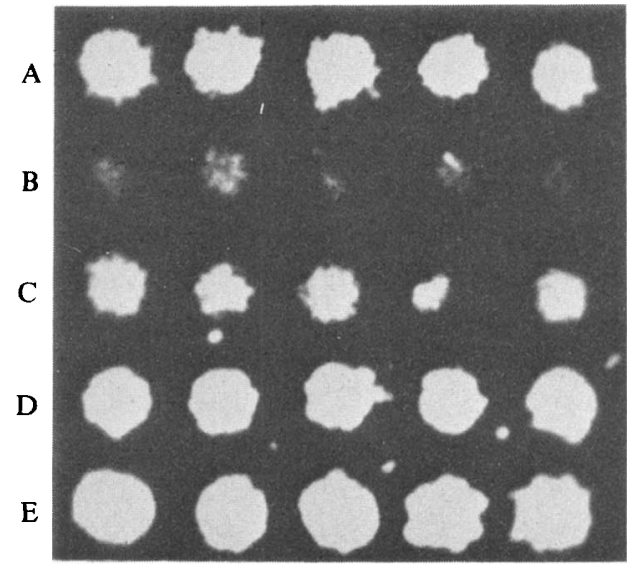

Fig. 3. Suppression of the ras2-530 phenotype by disruption of the $P B S 2$ gene. Cells were grown at $30^{\circ} \mathrm{C}$ on synthetic minimal medium plates with the necessary nutrients and replica-printed onto YPE medium ( $3 \%$ ethanol, $2 \%$ Bacto peptone, $1 \%$ yeast extract, $2 \%$ agar). The strains tested were as follows: A, JC482, wild-type; B, JC302-26B, ras $2-530 ; \mathrm{C}, \mathrm{GBH} 74$, ras2-530 pbs $2-1 ; \mathrm{D}, \mathrm{JC} 303-58$, ras2-530 yak1/SRA7; E, X10, ras2-530 yak1/SRA7 pbs2-1.

pheromone $\alpha$ (disruption of PBS2 may slightly enhance sensitivity). Therefore, a component of the yeast pheromone signalling pathway may be influenced by $P B S 2-$ dependent phosphorylation. However, although $P B S 2$ kinase belongs to the STE7 family of protein kinases (Hanks et al., 1988), and the STE7 gene is essential for mating in yeast (Teague et al., 1986), neither disruption nor overexpression of $P B S 2$ can restore mating ability to cells lacking a functional $S T E 7$ gene (data not shown). Variation in copy number of $P B S 2$ also has no effect on the activity of FUSI gene (Truehart et al., 1987; data not shown).

An important subset of signal transduction pathways is known to be regulated by two $R A S$ genes which act as 


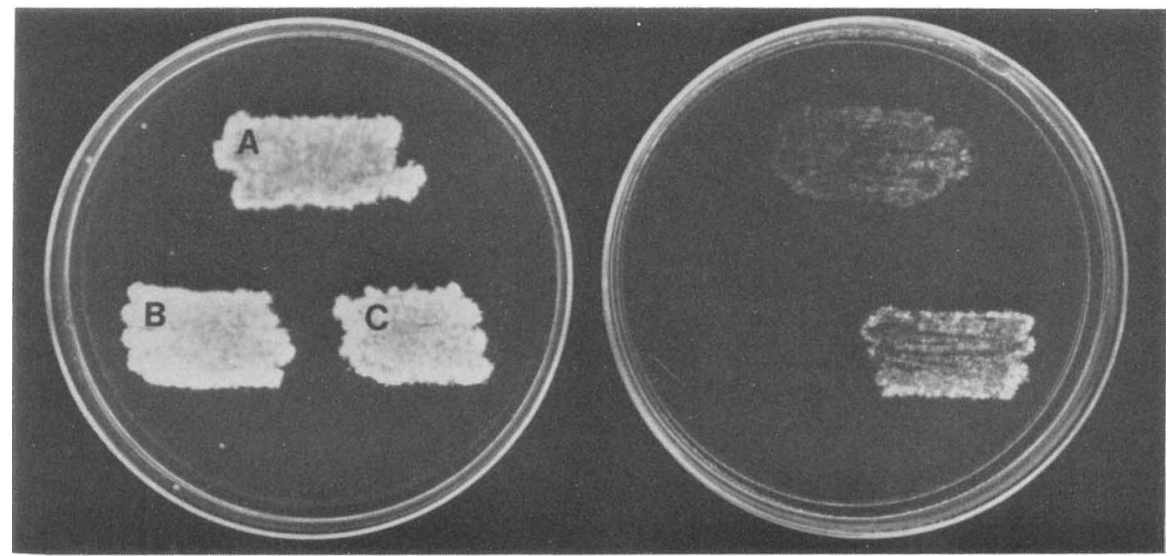

Fig. 4. Heat-shock sensitivity of $R A S 2^{V a l 19}$ mutant. Cells were incubated at $55^{\circ} \mathrm{C}$ for $40 \mathrm{~min}$, replicated onto YEPD, and incubated at $30^{\circ} \mathrm{C}$ for $24 \mathrm{~h}$. The left panel shows control plate, with cell patches not subjected to heating. The plate on the right shows the patches that had been heat-shocked. The patches are: A, TK161-R2V transformed with YEp24 vector; B, GBH65, RAS2Val19 pbs2-2; C, TK161-R2V transformed with YEp24.PBS2 plasmid.

modulators of adenylyl cyclase activity (Field et al., $1990 b$; Toda et al., 1985). Mutations in the RAS2 gene confer pleiotropic effects on cells (Cannon et al., 1986; Toda et al., 1985). These effects include a decrease in cyclic AMP (cAMP) levels, enhanced sporulation in rich media, and accumulation of storage carbohydrates such as glycogen. In addition, ras 2 mutants are unable to use nonfermentable carbon sources such as ethanol for growth (Cannon et al., 1986). However, these mutants grow very well on rich media such as YEPD that contain glucose as carbon source.

Disruption of the $P B S 2$ gene in the strain bearing a null allele of the $R A S 2$ gene (ras2-530::LEU2+) restores the ability of cells to grow on $3 \%$ ethanol (Fig. 3). However, the growth is not as robust as when a ras 2 suppressor mutation in another protein kinase gene yak 1 (Garrett \& Broach, 1989) is present; this gene has been described as $S R A 7$ by Cannon et al. (1986). In contrast to yak1/SRA7, pbs 2 at $37^{\circ} \mathrm{C}$ cannot suppress a cyr $1 / c d c 35$ (adenylyl cyclase) temperature-sensitive defect (cyrl-2 and $c d c 35-10$ alleles were tested) or a ras 1 ras 2 double mutation (not shown). The disruption neither enhances nor diminishes growth of the two cyrl mutants at room temperature. Although these negative results may be explained by the weak suppressive effect of $p b s 2$ (Fig. 3), they do suggest a possibility that $P B S 2$ acts downstream of or in parallel to RAS2 but not downstream of $C Y R 1$; they also indicate that the targets for yakl and pbs2 suppression are probably not related.

A dominant missense mutation that substitutes valine for glycine at position $19\left(R A S 2^{V a l 19}\right.$, activated $\left.R A S 2\right)$ results in an increased level of cAMP in the cells, poor sporulation, lack of carbohydrate accumulation, and loss of viability upon starvation or heating (Toda et al., 1985).

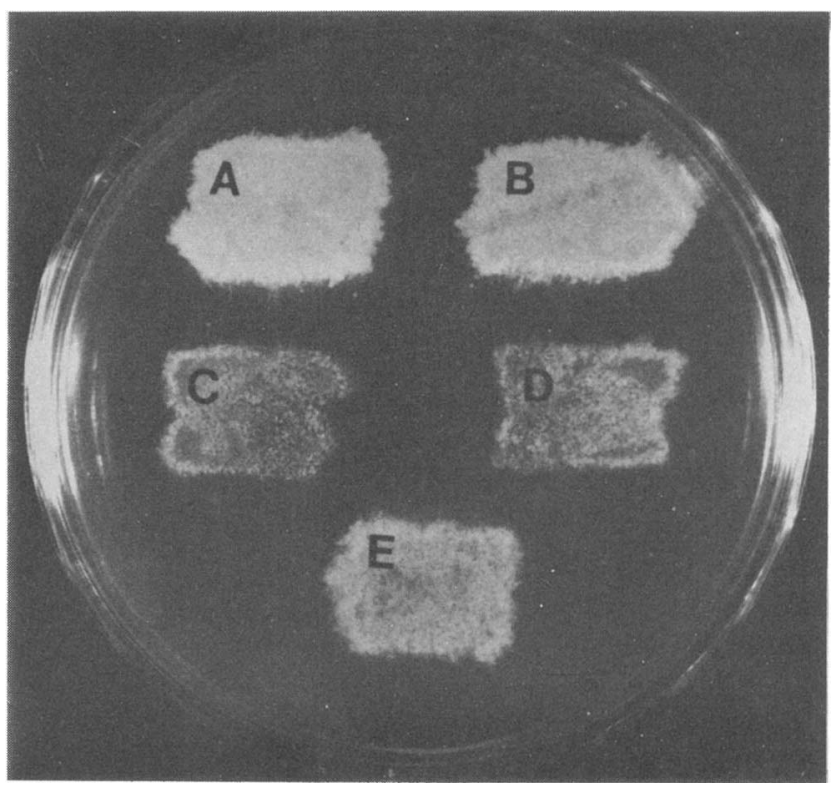

Fig. 5. Effect of disruption of the $P B S 2$ gene on the ability of yeast cells to grow on high osmolarity medium. Patches of cells were grown on YEPD and replicated onto YEPD containing $0.9 \mathrm{M}-\mathrm{NaCl}$ as described in Methods. The strains tested were as follows: A, YNN27 (wild-type); B, GBH21, pbs1-273, resistant to polymyxin B; C, GBH38, pbs2-2; D, GBH37, pbs1-273 pbs2-2; E, GBH46, pbs1-273 pbs2-2 $P B S^{r}$, polymyxin $B$ resistant revertant of strain GBH37 (see footnote to Table 1).

To assess the effects of changes in $P B S 2$ copy number on the viability of $R A S 2^{\text {Val } 19}$ mutants, the cells were transformed with either an integrating or an episomal plasmid (see Table 1) and subjected to a starvation regimen as described in Methods. The viability of the wild-type strain SP1 was excellent and appeared un- 

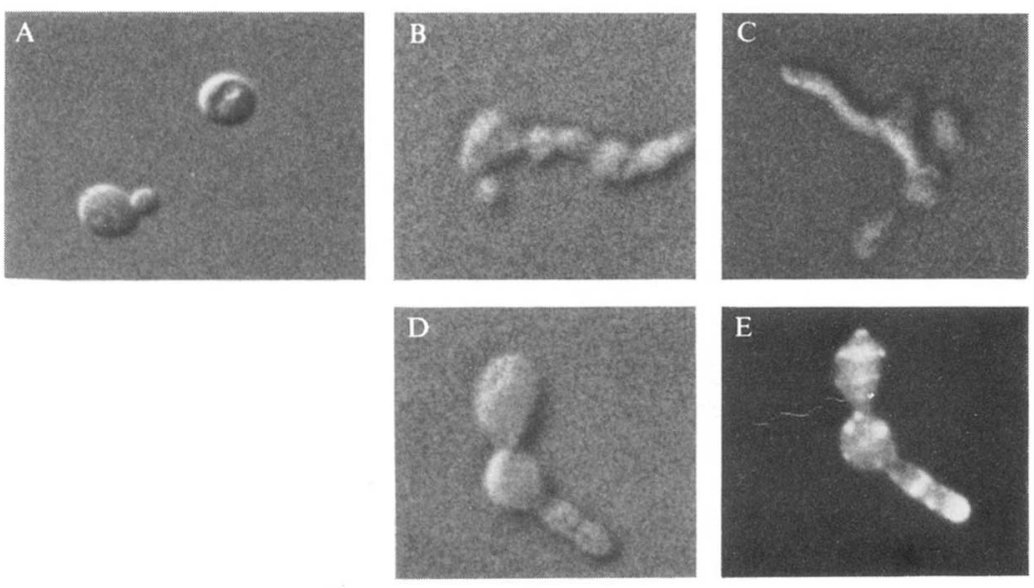

Fig. 6. Aberrant morphology of $p b s 2$ cells exposed to $0.9 \mathrm{M}-\mathrm{NaCl}$. Cells from patches shown in Fig. 5 were fixed with formaldehyde and examined microscopically as described in Methods. A, wildtype cells (YNN27). B, C, D, a variety of aberrant morphological forms of $p b s 2$ cells (GBH38). E, the same cell as in $D$, but stained with rhodamine-phalloidin to reveal actin distribution. affected by the condition of the $P B S 2$ allele (Table 2, unpublished data). In contrast, most cells of the activated $R A S 2$ mutant (strain TK161-R2V, quite unhealthy to begin with) died upon starvation. The survival of this strain was further depressed about fivefold by the $p b s 2$ deletion but was enhanced about threefold by overexpression of $\mathrm{PBS2}^{+}$(Table 2). These results are reinforced by the observation that pbs 2 disruption enhanced heat-shock sensitivity, whilst overexpression of $\mathrm{PBS2}^{+}$protected the cells from thermal death (Fig. 4).

Accumulation of glycogen by the various strains used in this study was examined by iodine staining (Cannon et $a l ., 1986)$. There was no effect either of overexpression of $P B S 2^{+}$or of $p b s 2$ disruption or deletion on the staining, and the pattern of glycogen accumulation followed that of the corresponding parent. Thus, regardless of the status of the PBS2 allele, ras2-530 colonies became dark brown when exposed to iodine vapour, while the $R A S 2^{\text {Val } 19}$ colonies remained straw yellow (data not shown). As with adenylyl cyclase mutants (cyrl), the lack of effect may be related to the weak suppression (perhaps because the threshold of sensitivity is different for growth on ethanol and carbohydrate accumulation). Nevertheless, $P B S 2$ suppression, or lack of it, provides an additional means of discriminating between the several cellular effects of the $R A S 2$ gene.

Polymyxin B is a membrane-active antibiotic, and genes controlling cellular responses to the drug may be logically thought to participate in membrane functions. One manifestation of membrane activity is osmoregulation or the ability of cells to cope with the increased salt concentration in the growth medium. As shown in Fig. 5, the wild-type cells and pbsl (polymyxin B resistant) mutant grew well when $0.9 \mathrm{M}-\mathrm{NaCl}$ was present. In contrast, a pbs 2 mutant and pbs 1 pbs 2 double mutants were unable to grow under such conditions (Fig. 5, C and D), and continued incubation resulted in death of these
Table 2. Viability of several yeast strains upon starvation in liquid medium

\begin{tabular}{llc}
\hline \hline Strain & Relevant genotype & Survival (\%) \\
\hline SP1 & Wild-type & $95 \cdot 3$ \\
TK161-R2V & RAS2 & 0.37 \\
TK161-R2V(YEp24.PBS2) & $R A S 2^{\text {Val 19 }} \mathrm{PBS2}^{+*}$ & 1.20 \\
GBH65 & RAS2 $^{\text {Val 19 }} \mathrm{pbs2-2}$ & 0.07 \\
\hline \hline
\end{tabular}

* $\mathrm{PBS2}^{+}$is overexpressed in cells transformed with YEp24.PBS2 plasmid.

cells. Microscopic examination of cells exposed to $0.9 \mathrm{M}$ $\mathrm{NaCl}$ revealed (Fig. 6) that pbs 2 mutant cells became morphologically aberrant, unable to form buds, but instead producing elongated, almost hypha-like extensions. However, as in normal cells, actin appeared to accumulate in the growing tip (Fig. 6, E). Cells grown in the absence of $\mathrm{NaCl}$ displayed normal morphology and viability (not shown). Interestingly, a strain selected as a polymyxin B resistant derivative of $p b s 1$ pbs 2 (i.e. bearing a suppressor of $p b s 2$ disruption) showed only weak growth on $0.9 \mathrm{M}-\mathrm{NaCl}$ (Fig. 5, E), even though its level of resistance to polymyxin $B$ equalled that of the pbsl parent. The suppressor strain, although clearly inhibited by the high salt concentration, was morphologically normal (data not shown). These results may be interpreted as meaning that the aberrant morphology is only partially related to osmotic sensitivity of the $p b s 2$ disruptant, and that involvement of $P B S 2$ kinase in antibiotic resistance could be separated from its role in osmoregulation. The above observations, coupled with suppression of $R A S 2$ mutations, suggest that $P B S 2$ is involved in several diverse physiological processes, all of which may relate to cell membrane function. 


\section{Discussion}

The results of this study indicate that the $R A S 2$ and $P B S 2$ genes may be involved in a common pathway. The fact that deletions of $P B S 2$ suppress the null ras2 phenotype of JC302-26B suggests that $P B S 2$ acts (negatively) on an element downstream of $R A S 2$; it also implies an antagonism between the products of the two genes. In addition, overexpression of $P B S 2$ weakens the effect of the enhanced $R A S 2$ activity of TK161-R2V, thus confirming the antagonistic relationship between $P B S 2$ and $R A S 2$. It is possible that $R A S 2$ is a negative regulator of $P B S 2$ activity; another possibility is that $R A S 2$ overcomes the negative effect of $P B S 2$ on a component downstream from these two genes (for example, by promoting dephosphorylation of that component). Alternatively or simultaneously, deletion of $P B S 2$ may allow derepression of $R A S 1$ gene that is normally repressed in the presence of nonfermentable carbon sources (Breviario et al., 1986), thus permitting growth of the ras 2 pbs 2 double mutant on ethanol. It is important to note that the suppression is not very strong, and that neither overexpression nor deletion of $P B S 2$ allows cells to bypass other $R A S$ functions or to restore a completely wild-type phenotype.

One cellular component directly downstream from $R A S 2$ is the adenylyl cyclase complex (encoded by $C Y R 1, C A P, I R A 1$, and perhaps other genes; FedorChaiken et al., 1990; Field et al., 1990a; Mitts et al., 1992, Vojtek et al., 1991). The RAS proteins control the activity of this complex (Fedor-Chaiken et al., 1990; Field et al., 1990a; Toda et al., 1985; Vojtek et al., 1991). Since $P B S 2$ deletion or overexpression cannot suppress mutations either in the $C Y R I(C D C 35)$ gene or in a double mutant ras1 ras2 (data not shown), changes in $P B S 2$ do not allow cells to bypass the cyclase step. Nevertheless, a specific interaction can be envisioned. It is possible that the antagonistic relationship between $R A S 2$ and $P B S 2$ is reflected, in part, in the phosphorylation-dephosphorylation state of the adenylyl cyclase complex: PBS2 kinase may down-modulate the complex activity, while $R A S 2$ could promote dephosphorylation. If so, in a ras 2 background, deletion of $P B S 2$ should decrease the amount of a phosphorylated complex, thereby enhancing its basal activity, and thus permitting the ras 2 mutant to grow on ethanol (Fig. 3). In $R A S 2^{\text {Val } 19}$ cells, in which constitutive activation of the adenylyl cyclase is the presumed reason for loss of viability upon starvation (Toda et al., 1985), diminished phosphorylation would lead to an increased cyclase activity (already enhanced by the activated RAS2 protein) and further depression of viability. Conversely, overexpression of PBS2 kinase would be expected to enhance cell survival (Table 2, Fig. 4), because it would counteract the overstimulation of the complex by the $R A S 2^{V a l 19}$ protein.

At least two additional cellular elements could be the targets for the $R A S 2-P B S 2$ pathway or for $P B S 2$ alone. First, as shown earlier (Fig. 2), overexpression of $P B S 2^{+}$ diminishes mating factor sensitivity. It may be significant that the pheromone response pathway in yeast is mediated by $\mathbf{G}$ proteins that share some structural and biochemical features with RAS proteins (Blumer \& Thorner, 1991). An independent suggestion of 'crosstalk' between the pheromone response elements and the RAS-adenylyl cyclase pathway has been recently presented by Arkinstall et al. (1991).

Second, as already pointed out, $P B S 2$ is essential for the expression of polymyxin B resistance of pbs 1 mutants (Boguslawski \& Polazzi, 1987). Thus, it is likely that the PBS1 gene product is another substrate for PBS2 kinase, and that resistance requires phosphorylation of the PBS1 product. However, other interpretations are possible. For example, it could be that the mutation in PBSI results in an increase in $P B S 2$ expression and, thus, resistance. Two pieces of evidence argue against this possibility. First, there is no difference in the amount of $P B S 2$ mRNA detectable in either wild-type or pbs 1 cells (data not shown), and previous results indicate that at least four copies of intact $P B S 2^{+}$are necessary to confer polymyxin B resistance in the wild-type, $P B S 1^{+}$, background (Boguslawski \& Polazzi, 1987). Therefore, at least fourfold (and probably higher) derepression of $P B S 2$ would have to result from $p b s 1$ mutation. Second, the resistance due to overexpression of $P B S 2^{+}$is not observed at $37^{\circ} \mathrm{C}$, whilst that due to $p b s 1$ mutation is equally strong at $25^{\circ} \mathrm{C}$ and $37^{\circ} \mathrm{C}$ (not shown). This means that the biochemical basis for resistance must be different in these two cases even though PBS2 kinase (single gene copy) is essential for expression of the pbslconferred resistant phenotype.

pbs 1 mutants are deficient in net potassium uptake (R. Gaber and G. Boguslawski, unpublished data). This observation opens an attractive (but speculative) prospect that $P B S 1$ encodes a (component of) a potassium channel that is dependent on the activities of the $R A S 2$ and $P B S 2$ genes. Such a possibility is supported by the evidence that animal RAS and other G proteins are linked to eukaryotic potassium channel activity and regulation (Birnbauer et al., 1990; Colin et al., 1990; Rane, 1991), that phosphorylation state affects potassium channel functioning (Rudy, 1988), and that polymyxin B inhibits calcium-activated potassium channels in mammalian cells (Varecka et al., 1987; Weik \& Lonnendonker, 1990). A very recent report (Schultz et al., 1992) demonstrates that potassium flux regulates adenylyl cyclase activity in Paramecium. The cloning and characterization of $P B S I$ will be necessary to determine 
whether and how the $R A S 2$ gene product might interact with potassium channels and with the molecules involved in polymyxin B resistance in yeast.

Addendum. While this work was in progress, I was informed by Dr Richard Kahn of the National Cancer Institute, Bethesda, MD, USA, that the previously reported sequence of PBS2 (Boguslawski \& Polazzi, $1987)$ is in error. The corrections are as follows: nucleotide 665 (C) is replaced by a G, and nucleotide 667 $(\mathrm{G})$ is replaced by a $\mathrm{C}$. These replacements change amino acids Ala222 and Val223 to Gly222 and Leu223, respectively. Further, an additional $\mathrm{T}$ residue is found in the nucleotide sequence at the position 2002 that results in a replacement of Tyr668 by Leu668 and in the appearance of a nonsense codon TAG immediately after the Leu668 residue. Therefore, the predicted PBS2 polypeptide contains 668 amino acids rather than the previously calculated 710 amino acids. The changes in the sequence have no bearing on the previous and current genetic data or on the surmised membership of the $P B S 2$ product in the protein kinase family.

This paper is dedicated to the memory of my mother.

I thank Richard Gaber for his thoughtful comments on the manuscript and Mark Goebl for allowing me to use his fluorescence microscope.

\section{References}

Adams, A. E. M. \& Pringle, J. R. (1991). Staining of actin with fluorochrome-conjugated phalloidin. Methods in Enzymology 194, 729-731

Amir, S. \& SheChter, Y. (1985). Polymyxin B is a potent inhibitor of insulin hypoglycemia in mice. European Journal of Pharmacology 110 , 283-285.

Amir, S., Sasson, S., Kaiser, N., Meyerovitch, J. \& Shechter, Y. (1987). Polymyxin B is an inhibitor of insulin-induced hypoglycemia in the whole animal model. Journal of Biological Chemistry 262, 66636667.

Arkinstall, S. J., Papasavyas, S. G. \& Payton, M. A. (1991). Yeast $\alpha$ mating factor receptor-linked G-protein signal transduction suppresses Ras-dependent activity. FEBS Letters 284, 123-128.

BEARER, E. L. \& Friend, D. S. (1980). Anionic lipid domains: correlation with functional topography in a mammalian cell membrane. Proceedings of the National Academy of Sciences of the United States of America 77, 6601-6605.

Birnbauer, L., Abramowitz, J., Yatani, A., Okabe, K., Mattera, R., Graf, R., Sanford, J., Codina, J. \& Brown, A. M. (1990). Roles of $\mathrm{G}$ proteins in coupling of receptors to ionic channels and other effector systems. CRC Critical Reviews in Biochemistry and Molecular Biology 25, 225-244.

BLUMER, K. J. \& THORNER, J. (1991). Receptor-G protein signaling in yeast. Annual Review of Physiology 53, 37-57.

BoGUSLAWSKI, G. (1985). Effects of polymyxin B sulfate and polymyxin B nonapeptide on growth and permeability of the yeast Saccharomyces cerevisiae. Molecular and General Genetics 199, 401405 .

BoGUSLAWSKI, G. (1986). Polymyxin B nonapeptide inhibits mating in Saccharomyces cerevisiae. Antimicrobial Agents and Chemotherapy 29, $330-332$.
Boguslawski, G. \& PolazzI, J. O. (1987). Complete nucleotide sequence of a gene conferring polymyxin $B$ resistance on yeast: similarity of the predicted polypeptide to protein kinases. Proceedings of the National Academy of Sciences of the United States of America 84, 5848-5852.

Brazil, O. V., Fontana, M. D. \& Pavani, N. J. P. (1989). Effect of 4aminopyridine on the post-synaptic action of polymyxin B. European Journal of Pharmacology 159, 47-51.

Breviario, D., Hinnebusch, A., Cannon, J. F., Tatchell, K. \& DHAR, R. (1986). Carbon source regulation of RAS1 expression in Saccharomyces cerevisiae and the phenotypes of ras2- cells. Proceedings of the National Academy of Sciences of the United States of America 83, 4152-4156.

Brown, D. R. \& TAYLOR, P. (1983). The influence of antibiotics on agonist occupation and functional states of the nicotinic acetylcholine receptor. Molecular Pharmacology 23, 8-16.

Cannon, J. F., GibBs, J. B. \& Tatchell, K. (1986). Suppressors of the RAS2 mutations of Saccharomyces cerevisiae. Genetics 113, 247-264.

Colin, C., Papageorge, A. G., Sakakibara, M., Huddie, P. L., LowY, D. R. \& ALKON, D. L. (1990). Early regulation of membrane excitability by ras oncogene proteins. Biophysical Journal 58, 785790.

Fedor-Chaiken, M., Deschenes, R. J. \& Broach, J. (1990). SRV2, a gene required for $R A S$ activation of adenylate cyclase in yeast. Cell 61, 329-340.

Field, J., Vojtek, A., Ballester, R., Bolger, C., Colicelli, J., Ferguson, K., Gerst, J., Kataoka, T., Michaeli, T., Powers, S., Riggs, M., Rodgers, L., Wieland, I., Wheland, B. \& Wigler, M. (1990a). Cloning and characterization of $C A P$, the $S$. cerevisiae gene encoding the $70 \mathrm{kD}$ adenylyl cyclase-associated protein. Cell 61, 319327.

Field, J., Xu, H.-P., Michaeli, T., Ballester, R., Sass, P., Wigler, M. \& COLICELLI, J. $(1990 b)$. Mutations of the adenylyl cyclase that block RAS function in Saccharomyces cerevisiae. Science 247, 464467.

GARRETT, S. \& BROACH, J. (1989). Loss of Ras activity in Saccharomyces cerevisiae is suppressed by disruptions of a new kinase gene, $Y A K 1$, whose product may act downstream of the cAMP-dependent protein kinase. Genes \& Development 3, 1336-1348.

Hanks, S. K., QuinN, A. R. \& HunTer, T. (1988). The protein kinase family: conserved features and deduced phylogeny of the catalytic domains. Science 241, 42-52.

Kubesh, P., Boggs, J., LuCiano, L., MAass, G. \& Tummler, B. (1987). Interaction of polymyxin $B$ nonapeptide with anionic phospholipids. Biochemistry 26, 2139-2149.

Mitts, M. R., Bradshaw-Rouse, J. \& Heideman, W. (1992). Interactions between adenylate cyclase and the yeast GTPaseactivating protein IRA1. Molecular and Cellular Biology 11, 45914598.

RANE, S. G. (1991). A Ca ${ }^{2+}$-activated $\mathrm{K}^{+}$current in ras-transformed fibroblasts is absent from nontransformed cells. American Journal of Physiology 260, C104-C112.

RUDY, B. (1988). Diversity and ubiquity of K channels. Neuroscience 25, 729-749.

SCHULTZ, J. E., KLUMPP, S., BenZ, R., SChuRHOFF-GoetTers, W. J. C. \& SCHMID, A. (1992). Regulation of adenylyl cyclase from Paramecium by an intrinsic potassium conductance. Science 255 , 600-603.

Sherman, F., Fink, G. R. \& Hicks, J. B. (1983). Methods in Yeast Genetics. Cold Spring Harbor, NY: Cold Spring Harbor Laboratory.

Singh, Y. N., Marshall, I. G. \& Harvey, A. L. (1980). The mechanism of the muscle paralyzing actions of antibiotics, and their interaction with neuromuscular blocking agents. Reviews in Drug Metabolism and Drug Interactions 3, 129-153.

Storm, D. E., Rosenthal, K. S. \& Swanson, P. E. (1977). Polymyxin and related peptide antibiotics. Annual Review of Biochemistry 46, 732-766.

Teague, M. A., Chaleff, D. T. \& Errede, B. (1986). Nucleotide sequence of the yeast regulatory gene $S T E 7$ predicts a protein homologous to protein kinases. Proceedings of the National Academy of Sciences of the United States of America 83, 7371-7375. 
Toda, T., Uno, I., Ishikawa, T., Powers, S., Kataoka, T., Broek, D., Cameron, S., Broach, J., Matsumoto, K. \& Wigler, M. (1985). In yeast, $R A S$ proteins are controlling elements of adenylate cyclase. Cell 40, 27-36.

Truehart, J., Boeke, J. D. \& Fink, G. R. (1987). Two genes required for cell fusion during yeast conjugation: evidence for a pheromoneinduced surface protein. Molecular and Cellular Biology 7, 23162328.

Varecka, L., Peterajova, E. \& Pogady, J. (1987). Polymyxin B, a novel inhibitor of red cell $\mathrm{Ca}^{2+}$-activated $\mathrm{K}^{+}$channel. FEBS Letters 225, 173-177.

Vojtek, A., HaArer, B., Field, J., Gerst, J., Pollard, T. D., Brown, S. \& WigleR, M. (1991). Evidence for a functional link between profilin and CAP in the yeast $S$. cerevisiae. Cell 66, 497-505.

WeIK, R. \& LoNNEndonker, U. (1990). Polymyxin B as a highly effective gating modifier of high-conductance $\mathrm{Ca}^{2+}$-activated $\mathrm{K}^{+}$ channels in mouse skeletal muscle. Pflugers Archiv 415, 671-677. 